\title{
Assessment of technical risk in maintenance and improvement of a manufacturing process
}

https://doi.org/10.1515/eng-2020-0047

Received Feb 13, 2020; accepted Mar 27, 2020

\begin{abstract}
Contemporary production companies operate in a dynamically changing environment and try to strengthen their competitive position. Therefore they take action acting at implementing new ones as well as improving and maintaining existing production processes, using for this purpose knowledge and available tools and methods. For dominant activities undertaken in the scope of improving and maintaining production the pro-quality activities can be included. Quality mainly depends on the efficiency of production processes, therefore manufacturing companies should focus their activities on maintaining and improving them. The methods of technical risk analysis and assessment are effective methods of maintaining production processes, whose application makes it possible to indicate any deviations from accepted standards. Analysis and assessment of the technical risk of the production process makes it possible not only to indicate nonconformities identified in the process, but mainly taking corrective actions. The aim of the article is to formulate of the method used to identify and assessment of the technical risk of the cutting process on the organizational side. The method has qualitative-quantitative type, and is the effective tools for technical risk assessment necessary to maintain the production process. It is assumed that the quality of the cutting process is ensured by the technical condition of the machine.
\end{abstract}

Keywords: production process, risk assessment, technical risk

\footnotetext{
*Corresponding Author: Ewa Kozień: Cracow University of Economics, College of Economics, Finance and Law, Institute of Economics, Department of Organization Development, ul. Rakowicka 27, 31-510 Cracow, Poland; Email: koziene@uek.krakow.pl; orcid: 0000-0002-5876-2804
}

๑ Open Access. ๑ 2020 E. Kozień, published by De Gruyter. (cc) $\mathbf{B Y}$ License

\section{Introduction}

Development of manufacturing organizations is connected with improvement and maintenance of manufacturing processes. The dominating approach of the manufacturing process improvement is its orientation on proquality activities, which enhance a competitive position of manufacturing companies acting in turbulent environment. Quality means a possibility of improvement of a manufacturing process and its products. European Quality Commission distinguished market quality connected with client assessment and utilitarian quality concerning the requirements arising from specific usable characteristics. In a scope of utilitarian quality, a quality of type and quality of workmanship were distinguished. Quality of type is referred to a collection of inherent properties (ISO 9000:2005), whereas quality of workmanship is created in a process of implementation (e.g. in a manufacturing process) pursuant to the adopted assumptions and taking into consideration a client's needs. A desired approach in maintenance of quality of workmanship in manufacturing processes is the application of methodology of technical risk management.

The technical risk management in maintenance of a manufacturing process as a significant element which has impact on indication of potential irregularities in a manufacturing process, which lead to an incidence of defects or faults in a manufactured product. In the article the attention was drawn to a fact that identification and technical risk assessment in a manufacturing process enables for undertaking remedial actions, contributing to the achievement of planned results as well as maintenance and improvement of a manufacturing process.

In quantitative analysis of machinery process, especially used to quality and risk estimation the commonly used in engineering are the methods of designing of experiments which beginning goes to R.A. Fisher [1]. The methods have been developed till today. They are discussed and reviewed e.g. by D.C. Montgomery [2]. The main limitation of this methods is related to the use of statistical mathematics and theory of probability in analyses. The probabilistic attempt is not sufficient when the data are few or individ- 
ual and knowledge of their values is inaccurate or incomplete [3]. One of the possible solution for the case when the number of data is low is application the non-parametric maximum likelihood estimation [4, 5]. In the end of XX century the method based on the fuzzy logic idea related to L.A. Zadeh [6] has been developed, having in mind the possibility of description of the so-called linguistic variable. The example of application of the idea to the ex-ante risk assessment in the project iss discussed by the author in [7], for interpretation of sequence of irregular data is discussed e.g. in [8] and for application of a fuzzy graph the algorithm based on fuzzy formal concept analysis is presented in [9]. Moreover in the analysis the methods of artificial intelligence and genetic algorithms are used [10]. The article [11] is dedicated to the problem od combine application of the genetic algorithms and fuzzy logic attempt. The other mathematically advanced methods which can be especially used to the estimation of class prevalence is based on novel algorithmic approach to content recommendation based on adaptive clustering of explorationexploitation (the so-called bandit) strategies [12-14]. The example of applications of mathematical modeling in risk assessment can be find e.g. in [15-17].

The purpose of this article is formulation of the method used to identify and assessment of the technical risk of the cutting process on the organizational side. The method has a qualitative-quantitative type. The essence of the company's operations is the timely execution of the order in accordance with the schedule and in accordance with the requirements specified in the order. It has been assumed that the quality of the cutting process, identified by keeping the geometric dimensions within the set tolerances, is ensured by the technical condition of the machine.

\section{The issue of technical risk}

Risk is a category of interdisciplinary character, which appears in all areas of human activity, therefore a natural need includes risk identification, measuring and management. Scientific approach to risk assessment arose from events which took place in history and their real impact on contemporary political, economic, social, cultural changes and technical progress. The development of scientific approach to an issue of risk was under the influence of a book published in 1921, written by F. Knight, entitled: Uncertainty and Profit, which drew the attention to differentiation of two notions, namely uncertainty and risk. F. Knight in his fundamental work separated the un- measurable sensu stricto uncertainty from measurable uncertainty, i.e. risk $[18,19]$. F. Knight began a scientific discourse regarding risk, which is continued in a scope of various scientific disciplines.

In a scope of management discipline, especially in its practical aspect, a risk is a key factor which has impact of effects of undertaken actions and a developmental potential of an organization [20]. Risk may be defined as combination of probability of occurrence of an event and its effects (ISO IEC Guide 73:2002) [21]. This general definition of risk is made more precise in two concepts distinguished in the professional literature, namely negative and neutral. Negative concept identifies a risk solely with hazard, loss, damage [22]. However, a neutral concept is based on an assumption that risk is neither negative nor positive [23]. It straightforwardly assumes that the occurrence of risk will make the achieved result of an action different than expected [24]. In management practice a sectoral approach may be noticed in a scope of identification and risk assessment, referring to selected areas $[25,26]$ and a holistic approach, identifying a collection of potential risks for the entire organization [27].

Generally the risk is perceived as measurable uncertainty which accompanies all actions undertaken in organizations. In the ISO 31000:2012 standard the risk is defined as impact of identified uncertainty on goals.

In the article the deliberations regarding the risk were restricted to technical risk in a scope of manufacturing processes implementation, whereas the technical risk was referred to hazards which may occur in a manufacturing process. These are the events which do not have a permanent and planned character. However, their occurrence causes interferences in a manufacturing process, what may contribute to a breakdown, irregularities or delays during the manufacturing of products. Exemplary reasons generating technical risk in manufacturing processes may be unverified or complex technologies, technological changes, new standards in an industry, inflated efficiency norms. Therefore, a goal of technical risk assessment in manufacturing processes is a reduction of probability of occurrence of undesired events by their elimination and monitoring of situations initiating their occurrence. Monitoring and restriction of occurrence of technical risk in a manufacturing process has impact on reduction of failure rates and defectiveness. Problem of assessment of current level of technical risk in a manufacturing process is reflected in a concept of a pyramid of events created by H. Heinrich, which involves the avoidance of „smaller caliber” events [28]. This approach is of essential significance in improvement and maintenance of manufacturing processes. In order to effec- 
tively manage the technical risk, one must employ a risk management methodology.

\section{Methodology of technical risk in a manufacturing process}

Risk assessment according to PN-ISO 31000:2012 is defined as an action which may be used in its range of significance both to an entirety of an organization, so therefore refers to its levels and areas of functioning, whereas towards its defined processes, functions, projects (PN-ISO 31000:2012). Pursuant to a definite research issue the risk analysis concerns the technical risk in a manufacturing process. In connection to more precise definition of a research scope a methodology of technical risk in manufacturing process was suggested, which include the following stages (Figure 1):

1. First stage - initial stage including the more precise definition of a scope of technical risk management, as well as a selection of methods and tools serving for its assessment.

2. Second stage - identification of technical risk, concerns the identification of its sources and potential effects, as well as development of a list of key hazards.

3. Third stage - analysis of technical risk is connected with definition of probability of occurrence of risks identified at a previous stage and assessment of its potential effects. Quality or quantity assessment of identified risks is made using methods defined at the first stage. At this stage the hierarchization of technical risk is performer, in order to define key risks.

4. Fourth stage - evaluation of technical risk is concentrated on undertaking optimal activities aiming at restriction and counteraction to key risks.

5. Fifth stage - proceeding with technical risk means undertaking actions defined at a previous stage. Moreover, control measures and monitoring is established, which are helpful in restriction of risk occurrence.

In improvement and maintenance of manufacturing processes the essential significance is attached to technical risk assessment of a manufacturing process, which in the suggested methodology is focused in a scope of actions undertaken in three stages: 2 - identification of risk, 3 risk analysis and 4 - evaluation of technical risk.

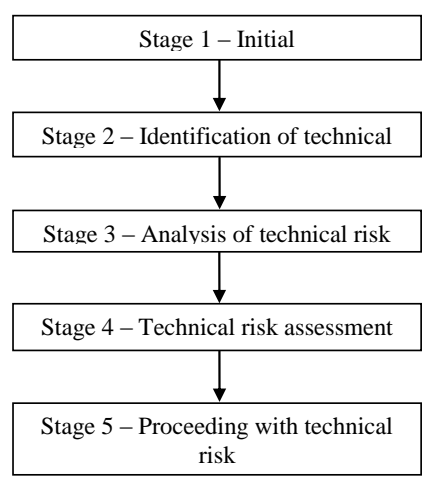

Figure 1: Methodology of technical risk assessment in a manufacturing process.

\section{Technical risk assessment on a basis of a manufacturing process - case study}

Pursuant to the methodology of technical risk assessment in a manufacturing process at an initial stage, a subject of analysis was defined, which refers to a manufacturing process of longitudinal cutting line of rings. In a manufacturing process three stages were distinguished: collection, unpacking and introduction of rings and packing and storage. Technical risk assessment was conducted for a cutting procedure.

The research was conducted for the technological process of longitudinal cutting carried out on cutting machines:

- cold-rolled, black, galvanized and coated steel strips: thickness $0.4-4 \mathrm{~mm}$, width $30-1650 \mathrm{~mm}$, yield strength up to $1000 \mathrm{MPa}$,

- hot-rolled, pickled steel strips: thickness 4-16 mm, width 45-2100 mm, yield strength up to $1000 \mathrm{MPa}$,

- cold-rolled, black, galvanized and hot-rolled, pickled sheets: thickness $0.4-3 \mathrm{~mm}$, width $600-$ $2020 \mathrm{~mm}$, length 150-6000 mm, yield strength up to $500 \mathrm{MPa}$,

- hot-rolled, black undigested and pickled sheets: thickness $1.5-20 \mathrm{~mm}$, width $650-2150 \mathrm{~mm}$, length 650-12000 mm, yield strength up to $900 \mathrm{MPa}$.

On a basis of analysis of a client's requirements concerning specifications of cutting and documents and procedures introduced in a manufacturing company regarding quality management, i.e. reasons of occurring defects and failures, three most essential hazards were identified in a manufacturing process for a cutting stage:

1. Installing improper or blunt knives in a knife fixture 
Table 1: Assessment of a degree of losses in a Preliminary Hazard Analysis (PHA) method

\begin{tabular}{ccc}
\hline Degree of damages (S) & Assessment & Level of probability (P) \\
\hline Insignificant damages & 1 & Insignificant, occurrence of incompliance highly \\
& & improbable \\
Small damages & 2 & Low, relatively few incompliances \\
Medium damages & 3 & Moderate, low incompliance \\
Large damages & 4 & High, frequent incompliance \\
Very large damages & 5 & Very high, permanent incompliance \\
\hline
\end{tabular}

Source: B. Chruszcz, J. Hansel [29]

Table 2: Assessment of technical risk for indicated hazards at a stage of cutting

\begin{tabular}{|c|c|c|c|c|}
\hline $\begin{array}{l}\text { Identified risks at } \\
\text { a stage of cutting }\end{array}$ & Consequences & $\begin{array}{l}\text { Degree of } \\
\text { damages } \\
\text { (S) }\end{array}$ & $\begin{array}{l}\text { Probability } \\
\text { level (P) }\end{array}$ & $\begin{array}{l}\text { Technical risk } \\
\text { assessment } \\
\text { (R) }\end{array}$ \\
\hline 1 & $\begin{array}{l}\text { - damage to material } \\
\text { - incompliance of material with quality requirements }\end{array}$ & 4 & 3 & 12 \\
\hline 2 & $\begin{array}{l}\text { - cutting the material without compliance with requirements defined in a } \\
\text { client's order } \\
\text { - client's complaint }\end{array}$ & 5 & 3 & 15 \\
\hline 3 & $\begin{array}{l}\text { - cutting the material in incompliance with an order } \\
\text { - destruction of material } \\
\text { - loss of time connected with repeated performance of an operation }\end{array}$ & 4 & 1 & 4 \\
\hline
\end{tabular}

2. Failure of separation rolls

3. Improper setting of cutting parameters

Next, in order to perform analysis and assessment of identified risks for a cutting stage a severity assessment and probability of occurrence of damages according to the adopted scale (Table 1).

Table 3: Matrix of valuing technical risk for a stage of cutting

\begin{tabular}{|c|c|c|c|c|c|c|}
\hline \multirow{7}{*}{ 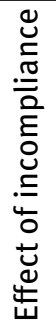 } & \multicolumn{6}{|c|}{ Level of probability of losses } \\
\hline & Level & 1 & 2 & 3 & 4 & 5 \\
\hline & 1 & & & & & \\
\hline & 2 & & & & & \\
\hline & 3 & & & & & \\
\hline & 4 & 3 ; & & 1 & & \\
\hline & 5 & & & 2 & & \\
\hline
\end{tabular}

Source: own sources

Results of analysis of identified hazards for a cutting process were presented in Table 2, where additionally the technical risk was assessed $\left(\mathrm{R}_{t}\right)$ according to a formula:

$$
R_{t}=S \cdot P
$$

where:

$S$ - degree of damages (1-5)

$\mathrm{P}$ - level of probability of occurrence of damages (1-5).

Following the assessment of parameters the technical risk was valued on a basis of a risk matrix (Table 3 ) on a basis of three indicated levels:

- first stage: 1-3 - acceptable risk,

- second stage: 4-9 - risk is admissible after verification,

- third level: 10-36 - unacceptable risk, preventive actions required.

On a basis of technical risk assessment of a manufacturing process concerning the cutting stage two unacceptable risks were identified, which refer to installation of improper or blunt knives in a fixture and occurrence of rolls breakdown. In face of identified hazards a preventive measure was undertaken, involving the implementation of a 
Table 4: Results of FMEA analysis for a procedure of cutting

\begin{tabular}{|c|c|c|c|c|c|c|c|c|c|}
\hline \multirow[t]{2}{*}{ Potential defects } & \multirow[t]{2}{*}{$\begin{array}{c}\text { Effects of } \\
\text { potential defects }\end{array}$} & \multirow[t]{2}{*}{ 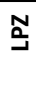 } & \multirow[t]{2}{*}{$\begin{array}{l}\text { Reasons for } \\
\text { potential defects }\end{array}$} & \multirow[t]{2}{*}{ 范 } & \multicolumn{2}{|c|}{$\begin{array}{c}\text { Methods of supervision of a } \\
\text { process }\end{array}$} & \multirow[t]{2}{*}{ 욤 } & \multirow[t]{2}{*}{ 呂 } & \multirow[t]{2}{*}{ Recommended actions } \\
\hline & & & & & Prevention & Detection & & & \\
\hline $\begin{array}{l}\text { Too wide, too } \\
\text { narrow cut, } \\
\text { incompliant with a } \\
\text { specificity of a } \\
\text { manufacturing } \\
\text { order }\end{array}$ & $\begin{array}{c}\text { Damage of } \\
\text { material Damage } \\
\text { of press Damage } \\
\text { of S-block rollers }\end{array}$ & 7 & $\begin{array}{c}\text { Error in preparation } \\
\text { of an order for } \\
\text { production }\end{array}$ & 6 & none & None & 8 & 336 & $\begin{array}{l}\text { Implementation of a } \\
\text { procedure of accepting orders } \\
\text { and preparation of technical } \\
\text { specifications Employee } \\
\text { training in a scope of } \\
\text { technical procedures }\end{array}$ \\
\hline Scratches, dents & $\begin{array}{l}\text { Damage of } \\
\text { material Client's } \\
\text { compliant }\end{array}$ & 8 & $\begin{array}{l}\text { Damage of S-block } \\
\text { rollers }\end{array}$ & 7 & $\begin{array}{l}\text { Replacement } \\
\text { of rollers }\end{array}$ & $\begin{array}{l}\text { Technical } \\
\text { review of a } \\
\text { machine }\end{array}$ & 3 & 168 & $\begin{array}{l}\text { Specification of a schedule of } \\
\text { machine servicing }\end{array}$ \\
\hline
\end{tabular}

Source: own material

Table 5: Impact of incompliance on effective implementation of a cutting process

\begin{tabular}{|c|c|c|c|}
\hline No. & Description of incompliance & Description of impact & $\begin{array}{c}\text { Assesment } \\
(1-10)\end{array}$ \\
\hline \multicolumn{4}{|c|}{ Machine failure } \\
\hline 1. & Operator's error at setting the rolls & Reduction of effectiveness of operations, hazard of causing machine failure and product damage & 10 \\
\hline 2. & $\begin{array}{l}\text { Damage of material during cutting } \\
\text { (blunt knives) }\end{array}$ & Reduction of operations effectiveness, product damage & 10 \\
\hline \multicolumn{4}{|c|}{ Impossibility of performance of manufacturing order } \\
\hline 3. & Error of setting a measuring device & Receipt of improper parameters of measurement & 10 \\
\hline \multicolumn{4}{|c|}{ Complaint } \\
\hline 4. & $\begin{array}{l}\text { Ignorance of procedures by an } \\
\text { employee }\end{array}$ & Risk of causing machine failure and product damage as well as client's compliant & 10 \\
\hline
\end{tabular}

schedule of knife quality control, technical inspection of a device and training employees in this aspect.

Bearing in mind the improvement of a cutting process one must take advantage of the Failure Mode and Effects Analysis (FMEA) to calculate the value of priority technical risk (LPR), which is a quotient of three parameters, the following formula was applied:

$$
L P R=L P W \cdot L P Z \cdot L P O
$$

where:

$L P W$ (value of priority occurrence) - assessment of defect occurrence frequency

$L P Z$ (value of priority significance) - assessment of defect significance

$L P O$ (value of priority detectability) - assessment of defect detectability

Criteria for coefficients LPW, LPZ, LPO, was defined in a scale from 1 to 10 .

FMEA analysis results indicated potential defects and incompliances in a process of cutting. Next, pursuant to the FMEA and PHA analysis, a FTA error-tree was developed, where the focus was concentrated only on basic events (incompliances) regarding operator's errors and improper use of a device in a process of cutting, as to which the conducted assessment of technical risk indicated a need for intervention. As a result of conducted analysis the hazards were grouped in an area of a device breakdown, problems with preservation of requirements of an order and a client's complaint, what was supposed to facilitate monitoring and proceeding with technical risk at a stage of cutting. In Table 5 the impact of incompliance on effective implementation of a cutting process was assessed.

Assessment of an impact of identified events on maintenance of a process of cutting constitutes the highest degree of hazard. Therefore, it is necessary to undertake interventions and remedial measures in order to restrict the occurrence of technical risk. Additionally, one may develop a checklist, based on which an internal audit should be conducted. In an event of occurrence of new hazards, the technical risk analysis and assessment of a process of cutting should be updated.

\section{Results and discussion}

The effect of technical risk identification and assessment are the pyramids of events, developed for groups of hazards in a process of cutting specified in Figure 2, Figure 3 and Figure 4.

The proposal of a methodology for technical risk assessment in the production process refers to organizational problems related to individual requirements of the clients. The assessment of technical risk at the stage of preparation and execution of the order according to the technical requirements of the ordering party is of particular importance from the point of view of efficient execution of orders. The proposed approach to technical risk as- 


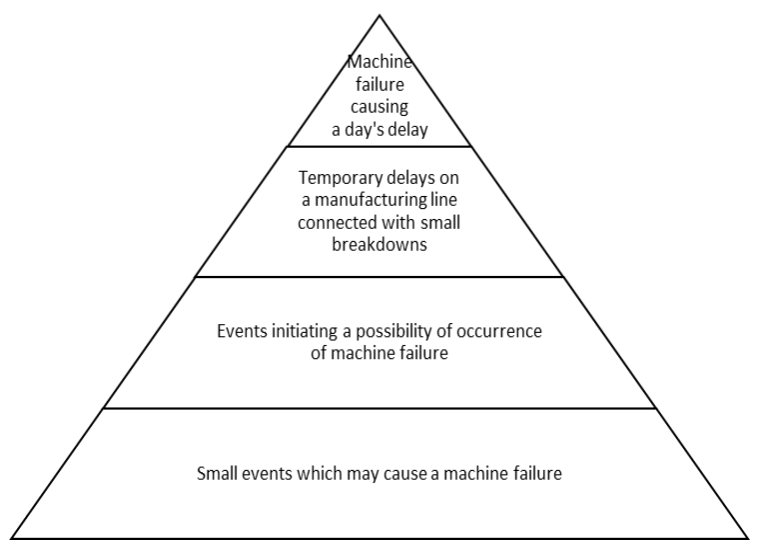

Figure 2: Pyramid of potential events in a machine failure Source: B. Eckhardt [28]

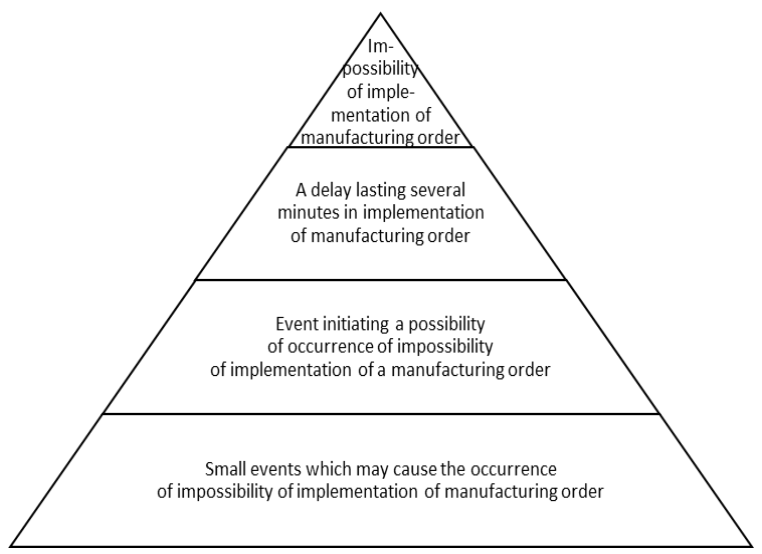

Figure 3: Pyramid of events of impossibility of implementation of an order

Source: B. Eskhardt [28]

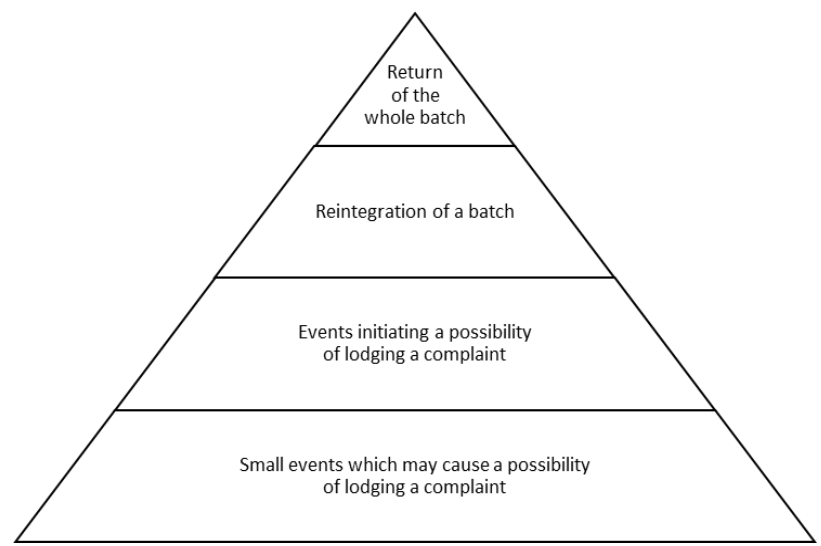

Figure 4: Pyramid of events of complaints

Source: B. Eckhardt [28]

sessment in terms of developing an efficient order execution procedure in the company, effectively reduces organizational errors and allows optimization of time and costs of order execution. The proposed methodology of technical risk assessment is to draw attention to the importance, besides the technological dimension of production processes, of the organizational dimension, which is a part of the contemporary trend of process improvement.

A novelity in the approach to technical risk assessment in the extension of performance quality assessment in production processes to the organizational dimension.

\section{Conclusions}

Assessment of technical risk in a manufacturing process is a key problem for its maintenance and improvement. In identification and assessment of technical risk in a manufacturing process one should use active and reactive approach. Active approach involves identification of all potential hazards already at an early stage of preparation of a manufacturing process in order to undertake actions preventing or minimizing their impact on end effects of a process. This means that at an initial stage it is appropriate to perform the ex ante assessment of technical risk. However, in a scope of occurrence during the implementation of a manufacturing process of risks unidentified at an initial manufacturing stage the reactive approach should be applied, what means the ongoing undertaking of remedial measures aimed at elimination or restriction of risks which may have impact on a course of a process and obtaining full-valued products. In a course of a manufacturing process it is necessary to perform technical risk on-line assessment. Technical risk assessment requires from manufacturing companies of a holistic approach including the use and adjustment of methods of its assessment at every stage of a manufacturing process. Technical risk assessment in a manufacturing process is an ongoing process connected with a chance of obtaining planned quality of a product.

Technical risk assessment in manufacturing processes is a difficult issue on account of shortening manufacturing cycles, implementation of individual requirements of clients, technical progress is also a challenge for managers and employees in a scope of development of methodologies and procedures of effective implementation of a manufacturing process with maintenance of planned quality.

The proposed technical risk assessment, focused on the organizational dimension is simply and fast. The method does not require a lot of cost and time, and may be carried out ex-ante. An important advantage of the method is the assessment of technical risk given in quantitative terms and the final preparation of the so called pyramids of events. which are helpful for process managers in eliminat- 
ing possible causes of bad process implementation. It may be added that methods that can be carried out on-line and, in principle ex-post, which are advanced, also in terms of mathematical background, may include: fuzzy logic attempt, artificial intelligence, genetic algorithms, adaptive clustering of exploration-exploitation strategies. The analysis of the application of these methods goes beyond the aim and scope of the paper.

\section{References}

[1] Fisher RA. The Design of Experiments. Edinburgh: Oliver and Boyd Press; 1935.

[2] Montgomery DC. Design and analysis of experiment. New York: John Wiley and Sons; 2004.

[3] Pietraszek J. Metody planowania badań doświadczalnych eksploatowanych maszyn i urządzeń. Monografia nr 378. Kraków: Wydawnictwo Politechniki Krakowskiej; 2010 [in Polish].

[4] Owen AB. Empirical Likelihood. Boca Raton: CRC Press; 2001. https://doi.org/10.1201/9781420036152.

[5] Pietraszek J, Dwornicka R, Krawczyk M, Kolomycki M. The nonparametric approach to the quantification of the uncertainity in the design of experiments modelling. In: Papadrakakis M, Papadopoulos V, Stefanou G, editors. UNCECOMP 2017: Proceedings of the 2nd International Conference on Uncertainty Quantification in Computational Sciences and Engineering; 2017 Jun 15-17; Rhodes Island, Greece. Athens: Institute of Structural Analysis and Antiseismic Research. School of Civil Engineering. National Technical University of Athens; 2017. p. 598-604.

[6] Zadeh LA. Probability measures of fuzzy events. J Math Anal Appl. 1968;23(2):421-7.

[7] Kozien E, Kozien MS. Using the fuzzy logic description for the ex-ante risk assessment in the project. In: Ribeiro H, Naletina D, Lorga da Silva A., editors. Economic and Social Development. Book of Proceedings: 35th International Scientific Conference on Economic and Social Development; 2018 Nov 15-16; Lisbon, Portugal. Varazdin: Varazdin Development and Entrepreneurship Agency; 2018. p. 224-31.

[8] Pietraszek J, Sobczyk A, Skrzypczak-Pietraszek E, Kolomycki M. The fuzzy interpretation of the statistical test for irregular data. Technical Transactions. 2016;113(14):119-26.

[9] Hao F, Park DS, Li S, Lee HM. Mining $\lambda$-Maximal Cliques from a Fuzzy Graph. Sustainability. 2016;8(6):553.

[10] De Jong KA. Evolutionary Computation. A Unified Approach. Cambridge: MIT Press; 2006.

[11] Guo H, Feng Y, Hao F, Zhong S, Li S. Dynamic Fuzzy Logic Control of Genetic Algorithm Probabilities. J Comput (Taipei). 2014 Jan;9(1):22-7.
[12] Li S. The Art of Clustering Bandits [dissertation]. Varese: University of Insubria, Department of Theoretical and Applied Sciences; 2016.

[13] Li S, Karatzoglou A, Gentile C. Collaborative Filtering Bandits. In: SIGIR'16: Proceedings of the $39^{\text {th }}$ International ACM SIGIR Conference on Research and development in Information Retrieval; 2016 Jul 17-21; Pisa, Italy. ACM; 2016: p. 539-48.

[14] Korda N, Szorenyi B, Li S. Distributed Clustering of Linear Bandits in Peer to Peer Networks. Proceedings of the $33^{\text {rd }}$ International Conference on Machine Learning ICML 2016; 2016 Jun 19-24; New York, NY, USA. 2016: JMLR: W\&CP volume 48: p. 1301-9.

[15] Shang K, Hossen Z. Applying fuzzy logic to risk assessment and decision-making. Casuality Actuarial Society, Canadian Institute of Actuaries, Society of Actuaries; 2013.

[16] Shapiro AF, Koissi MC. Risk assessment applications of fuzzy logic. Casuality Actuarial Society, Canadian Institute of Actuaries, Society of Actuaries; 2015.

[17] Kozien E, Kozien MS. Ex-Ante Risk Estimation in the Production Project. Sciendo, System safety: Human - Technical Facility Environment. 2019;1(1):708-15. https://doi.org/10.2478/czoto2019-0090.

[18] Knight F. Risk, Uncertainty and Profit. New York: Dover Publication Inc.; 2006.

[19] De Meyer A, Loch C, Pich M. Managing project uncertainty. From variation to chaos. MIT Sloan Manag Rev. 2002;43(2):60-7.

[20] Kozien E. Identification of stage phase growth in the checklist method using different statistical parameters. In: Yongqiang L., Hunjet A., Roncevic, A., editors. Economic and Social Development. Book of Proceedings: 20th International Scientific Conference on Economic and Social Development; 2017 Apr 27-28; Prague, Czech Republic. Varazdin: Varazdin Development and Entrepreneurship Agency; 2017. p. 538-45.

[21] Federation of European Risk Management Associations. Risk Management Standard. Brussels: The Assotiations; 2003.

[22] Wilson D. Risk. Wiley Encyclopedia of Management, 12: Strategic Management. Oxford: Blackwell Publishing; 2005.

[23] Jajuga K. Zarządzanie ryzykiem. Warszawa: PWN; 2007 [in Polish].

[24] Kaczmarek T. Zarządzanie ryzykiem handlowym, finansowym, produkcyjnym dla praktyków. Gdansk: ODiTK; 2002.

[25] Bannister JE, Bawcutt PA. Practical risk management. Livingstone: Witherby; 1981.

[26] Kloman HF. Rethinking risk management. Geneva Pap Risk Insur Issues Pract. 1992;17(3):299-313.

[27] Bromiley P, McShane M, Nair A, Rustambekov E. Enterprise risk management: Reviev, Critique, and Research Directions. Long Range Plann. 2015;48(4):265-76.

[28] Eckhardt B. Reevaluating the incident pyramid. Concrete Products. 2003 May;106(5):38-40.

[29] Chrószcz B, Hansel J. Analiza i ocena ryzyka zawodowego. Kraków: Wydawnictwa AGH; 2011 [in Polish]. 